\title{
High-content analysis of proteostasis capacity in cellular models of amyotrophic lateral sclerosis (ALS).
}

Isabella A. Lambert-Smith ${ }^{1,2}$, Justin J. Yerbury ${ }^{1,2}$, Darren N. Saunders ${ }^{1}$

1. Illawarra Health and Medical Research Institute, University of Wollongong, Wollongong, NSW 2522 Australia

2. School of Chemistry and Molecular Bioscience, University of Wollongong, Wollongong, NSW 2522 Australia

\section{Corresponding author:}

Darren N. Saunders, Illawarra Health and Medical Research Institute, University of Wollongong, Wollongong, NSW 2522 Australia

Email: dnsaunders@,icloud.com

\section{Highlights}

- Destabilised firefly luciferase (Fluc) mutants can be used in high-content analysis (HCA) assay format

- Fluc HCA assay enables information-rich reporting on chaperone network activity in cell models of ALS

- Expression of SOD $1^{\mathrm{A} 4 \mathrm{~V}}$ reduces chaperone network activity in NSC-34 cells

\begin{abstract}
Disrupted proteome homeostasis (proteostasis) in amyotrophic lateral sclerosis (ALS) has been a major focus of research in the past two decades. Yet the exact processes that normally maintain proteostasis, but that are uniquely disturbed in motor neurons expressing diverse genetic mutations, remain to be established. Obtaining a better understanding of proteostasis disruption in association with different ALS-causing mutations will improve our understanding of ALS pathophysiology and may identify novel therapeutic targets and strategies for ALS patients. Here we describe the development and use of a novel high-content analysis (HCA) assay to investigate proteostasis disturbances caused by the expression of ALS-causing gene variants. This assay involves the use of conformationally-destabilised mutants of firefly luciferase (Fluc) to examine protein folding/re-folding capacity in NSC-34 cells expressing ALS-associated mutations in the genes encoding superoxide dismutase- 1 (SOD1 ${ }^{\mathrm{A} 4 \mathrm{~V}}$ ) and cyclin $\mathrm{F}\left(\mathrm{CCNF}^{\mathrm{S} 621 \mathrm{G}}\right)$. We demonstrate that these Fluc isoforms can be used in high-throughput format to report on reductions in the activity of the chaperone network that result from the expression of $\mathrm{SOD}^{\mathrm{A} 4 \mathrm{~V}}$, providing multiplexed information at single-cell resolution. In addition to $\mathrm{SOD}^{\mathrm{A} 4 \mathrm{~V}}$ and $\mathrm{CCNF}^{\mathrm{S} 621 \mathrm{G}}$, NSC-34 models of ALS-associated TDP-43, FUS, UBQLN2, OPTN, VCP and VAPB mutants were generated that could be screened using this assay in future work. For ALS-associated mutant proteins that do cause reductions in protein quality control capacity, such as SOD1 ${ }^{\mathrm{A} 4 \mathrm{~V}}$, this assay has potential to be applied in drug screening studies to identify candidate compounds that can ameliorate this deficiency.
\end{abstract}




\section{Graphical abstract}

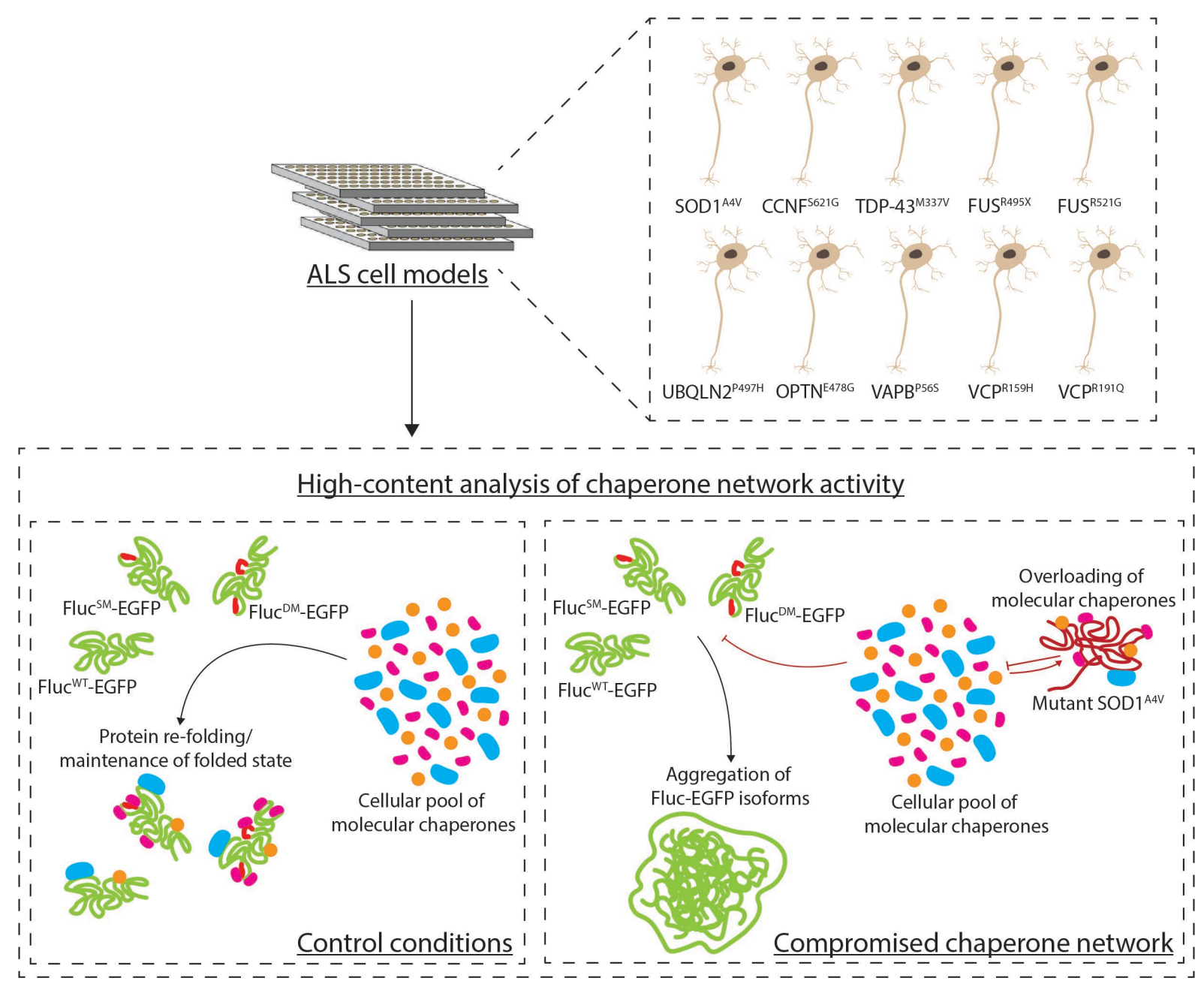

\section{Keywords}

Amyotrophic lateral sclerosis, cyclin F, neurodegeneration, proteostasis, superoxide dismutase-1. 


\section{INTRODUCTION}

Post-mortem examination of spinal cord tissue from amyotrophic lateral sclerosis (ALS) patients consistently reveals the presence of TDP-43-, FUS- or SOD1- and ubiquitin-positive inclusions comprised of insoluble proteinaceous material [1-4]. Misfolded proteins, as either abnormal monomers and/or oligomeric precursors, possess cytotoxic properties [5-7] and their aggregation into certain kinds of inclusions may serve to protect cells and to assist in the clearance of these toxic species [8-17]. There is strong evidence that the progressive spread of pathology in patients could be due to the cell-to-cell propagation of protein misfolding and aggregation [18, 19]. However, the formation of protein inclusions is also indicative of dysregulated protein homeostasis (proteostasis) [20,21] and the inability of the cell to properly monitor, refold or degrade non-native proteins.

Given the genetic and functional heterogeneity of ALS, the development of high content assays that can measure multiple phenotypic features in cellular ALS models and extract rich, descriptive information of responses to candidate therapeutic compounds and modifiers of ALS gene toxicity will be valuable. To address this need, we have developed an experimental system with HCA capacity that can be used to extract multiplexed phenotypic data from cellular ALS models. In the present work we have tested this system to examine proteostasis capacity in cellular models of SOD1- and CCNF-linked ALS. 


\section{MATERIALS AND METHODS}

\subsection{Plasmids}

All plasmids are detailed in the Supplementary Material.

\subsection{Cell culture}

NSC-34 cells [22] were maintained in 10\% (v/v) fetal bovine serum (FBS; Bovogen Biologicals) in Dulbecco's Modified Eagle's Medium/Ham's Nutrient Mixture F-12 (DMEM/F-12). Cells were seeded into either 8-well $\mu$-Slides (Ibidi) for confocal microscopy or 96-well plates (Greiner Bio-One) for imaging using the Cellomics ArrayScan VTI imaging platform (Thermo Scientific). After overnight incubation at $37{ }^{\circ} \mathrm{C}$ under $5 \% \mathrm{CO}_{2} / 95 \%$ air, cells were either single-transfected or triple-transfected (detailed in Tables S1 and S2, supplementary information) using Lipofectamine 2000 (Invitrogen) according to manufacturer's instructions. For triple transfections, plasmids were used at a 1: 1: 1 ratio. All transfection conditions were carried out in quadruplicate. For experiments involving proteasome inhibition, MG132 was solubilised in DMSO at $20 \mathrm{mM}$ and subsequently diluted to $5 \mu \mathrm{M}$ in $10 \%(\mathrm{v} / \mathrm{v}) \mathrm{FBS}$ in DMEM/F-12. The prepared solution was added to cells $30 \mathrm{~h}$ posttransfection and incubated for $18 \mathrm{~h}$.

\subsection{Confocal microscopy}

Localisation of each fusion protein in transfected NSC-34 cells was characterised by imaging using a TCS SP5 II confocal microscope with a $63 \times$ oil-immersion objective lens (Leica Microsystems). Imaging was carried out $48 \mathrm{~h}$ post-transfection.

\subsection{High-content analysis}

NSC-34 cells were imaged either live or fixed (in 4\% (w/v) paraformaldehyde for $20 \mathrm{~min}$ at room temperature) using the $20 \times$ objective of a Cellomics ArrayScan VTI imaging platform (Thermo Scientific). All assays described are appropriate for either live or fixed cell imaging. Fluorescence of ECFP-, EGFP- and tdT/mCherry-fusion proteins was imaged using excitation filters of $386 \mathrm{~nm}, 485 \mathrm{~nm}$ and $549 \mathrm{~nm}$, respectively. Phase contrast and fluorescent images from 20 fields of view per well were acquired, with image analysis parameters optimised using the SpotDetector V4 BioApplication in HCS Studio (Thermo Scientific) summarised in Figure 1 (further detail in Figure S1). Primary object identification was based on expression of H2BECFP in channel 1, while GFP or tdTomato/mCherry-fusion proteins were detected in channels 2 and 3. 
bioRxiv preprint doi: https://doi.org/10.1101/2021.09.23.461468; this version posted September 23, 2021. The copyright holder for this preprint (which was not certified by peer review) is the author/funder. All rights reserved. No reuse allowed without permission.
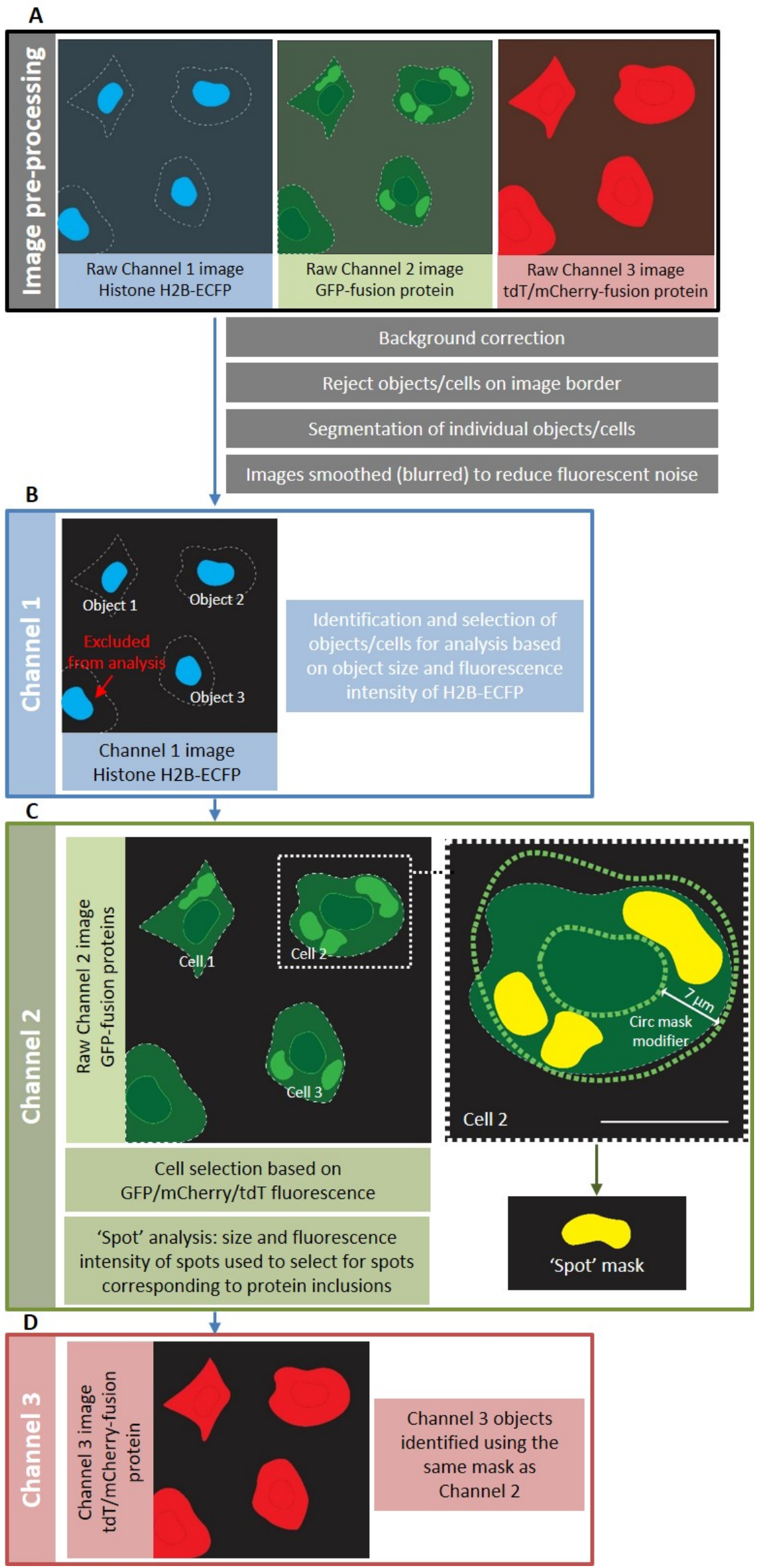
bioRxiv preprint doi: https://doi.org/10.1101/2021.09.23.461468; this version posted September 23, 2021. The copyright holder for this preprint (which was not certified by peer review) is the author/funder. All rights reserved. No reuse allowed without permission.

Figure 1. Schematic of High Content Analysis (HCA) image processing and analysis optimisation. To analyse the fluorescence intensity of EGFP-/tGFP- and tdTomato (tdT)/mCherry-fusion proteins and quantify protein inclusions containing EGFP-/tGFP-fusion proteins in NSC-34 cells, we deployed the Spot Detector BioApplication designed to analyse fluorescent foci in cells. Optimisation was carried out using images of NSC34 cells triple-transfected to express H2B-ECFP, either SOD $1^{\mathrm{WT}}$-EGFP, SOD ${ }^{\mathrm{A} 4 \mathrm{~V}}$-EGFP, TDP-43 ${ }^{\mathrm{WT}}$-tGFP TDP$43^{\mathrm{M} 337 \mathrm{~V}}$-tGFP, FUS ${ }^{\mathrm{WT}}$-tGFP, FUS ${ }^{\mathrm{R} 495 \mathrm{X}}$-tGFP, FUS ${ }^{\mathrm{R} 521 \mathrm{G}}$-tGFP or EGFP alone and mCherry alone. Cells were imaged at $48 \mathrm{~h}$ post-transfection using a $20 \times$ objective lens. (A) Raw images from Channels 1 (H2B-ECFP), 2 (EGFP-/tGFP-fusion proteins) and 3 (tdTomato/mCherry-fusion proteins) were first pre-processed to remove background fluorescence, exclude cells positioned on the border of each image from analysis and distinguish individual cells ('object' segmentation). Channel 1 images were additionally smoothed (blurred) to help reduce fluorescent noise that could lead to the false inclusion of image artefacts in subsequent analyses. (B) Biological 'objects', in this case cells, were identified using nuclear-localised H2B-ECFP fluorescence in Channel 1 images. To select viable transfected cells for analysis and exclude image artefacts, dead cells and cell debris, cells were selected based on the size and fluorescence intensity of their ECFP-fluorescent nuclei. (C) The relevant measures for GFP fluorescence intensity and fluorescent foci were measured in Channel 2 within a circular analysis mask that expanded the mask derived in Channel 1. The green circular mask indicates cells selected for analysis, while yellow masks indicate fluorescent foci/'spots' selected for analysis. To detect and analyse fluorescent foci corresponding to protein inclusions, upper and lower limits for size and fluorescence intensity were set. (D) Channel 3 objects were identified using the same mask as Channel 2. 


\section{RESULTS}

\subsection{Characterisation of cellular ALS models}

Given the extraordinary molecular heterogeneity of ALS, we developed a suite of ALS models representing genetically diverse fALS aetiologies in NSC-34 cells expressing EGFP-/tGFP/mCherry-fusions of mutant SOD1, TDP-43, FUS, CCNF, UBQLN2, OPTN, VCP or VAPB. The genetic mutations for these models were selected after careful consideration of the mutations that segregate with ALS; SODI ${ }^{A 4 V}$ [23], TARDBP ${ }^{M 337 V}$ [24], FUS ${ }^{R 495 X}$, FUS ${ }^{R 521 G}$ [3, 4], $C C N F^{S 621 G}$ [25], UBQLN2 $2^{P 497 H}$ [26], OPTN ${ }^{E 478 G}$ [27], $V A P B^{P 56 S}$ [28], $V C P^{R 159 H}$ and $V C P^{R 191 Q}$ [29]. Prior to using these NSC-34 models in an HCA format, we first characterised the localisation, toxicity, and solubility of each WT and mutant fusion protein (Figure S3-S7). Importantly, EGFP and mCherry were diffusely distributed throughout the cell and did not aggregate (Figure S2, a, i and b, i). It was also confirmed that the expression of EGFP or mCherry-alone had no effect on cell viability (Figure S2, a, ii and b, ii).

\subsection{Toxicity of mutant SOD1, TDP-43, FUS and CCNF}

Live cell imaging of cells expressing SOD $1^{\mathrm{WT}}$-EGFP and SOD $1^{\mathrm{A} 4 \mathrm{~V}}$-EGFP to monitor cell population growth showed that the numbers of cells expressing SOD1 ${ }^{\text {WT }}$-EGFP and EGFPalone steadily increased, while the numbers of cells expressing SOD1 ${ }^{\mathrm{A} 4 \mathrm{~V}}$-EGFP increased at a slower rate (Figure 2, a, iii). At $48 \mathrm{~h}$ post-replating there were significantly lower numbers of cells expressing SOD1 ${ }^{\mathrm{A} 4 \mathrm{~V}}$-EGFP than SOD1 ${ }^{\mathrm{WT}}$-EGFP $(p=0.0151)$ (Figure 2 , a, iv). This indicates that the overexpression of SOD $1^{\mathrm{A} 4 \mathrm{~V}}$-EGFP caused toxicity.

A similar trend was observed for cells expressing TDP-43, FUS or CCNF. Comparison of the mean numbers of GFP/RFP-positive transfected cells at $72 \mathrm{~h}$ post-transfection showed that there was a significantly greater number of cells expressing WT proteins than cells expressing mutants (TDP-43 ${ }^{\mathrm{M} 337 \mathrm{~V}}$-tGFP, $p<0.001$; FUS ${ }^{\mathrm{R} 495 \mathrm{X}}$-tGFP, $p=0.0014$; FUS ${ }^{\mathrm{R} 521 \mathrm{G}}$-tGFP, $p=$ 0.0023; $\mathrm{CCNF}^{\mathrm{S} 621 \mathrm{G}}$-mCherry, $p<0.0001$ ) (Figure 2, b-d, iv). 


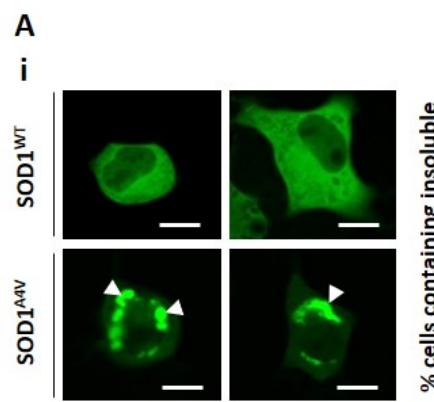

B

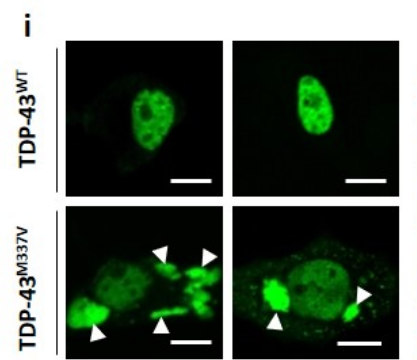

C

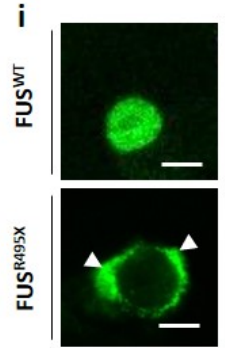

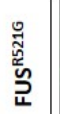

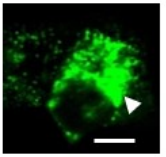

D

i
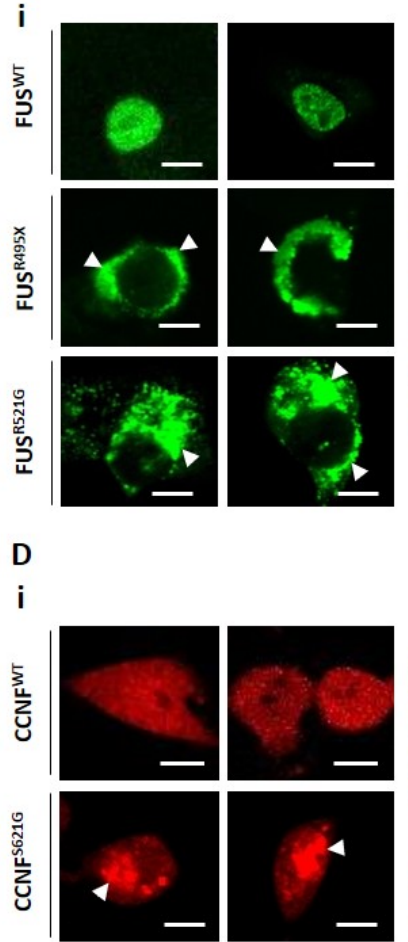

ii

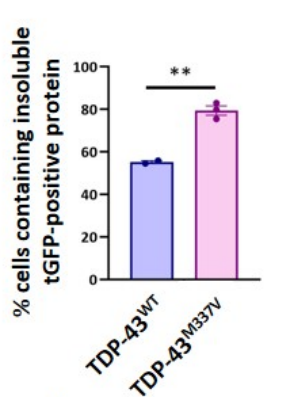

ii
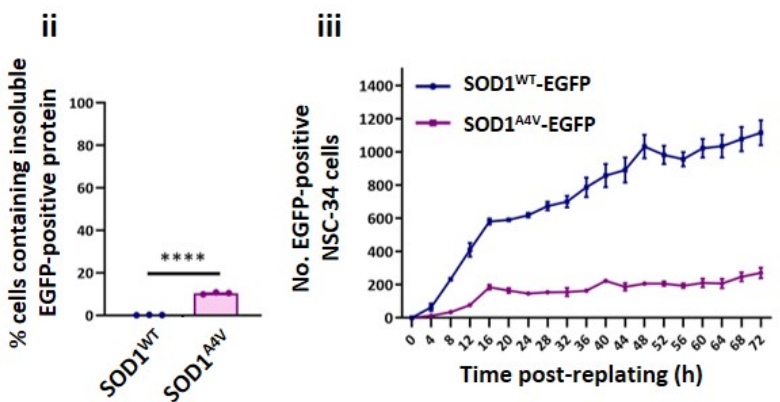

iii

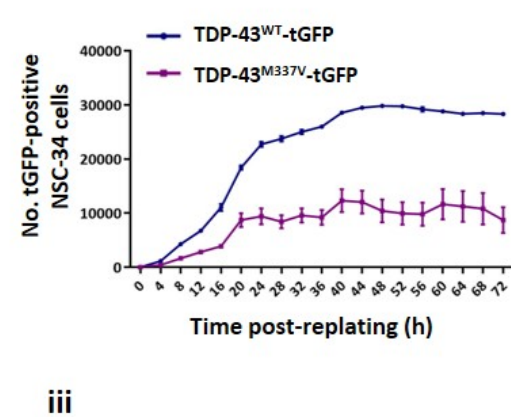

iii
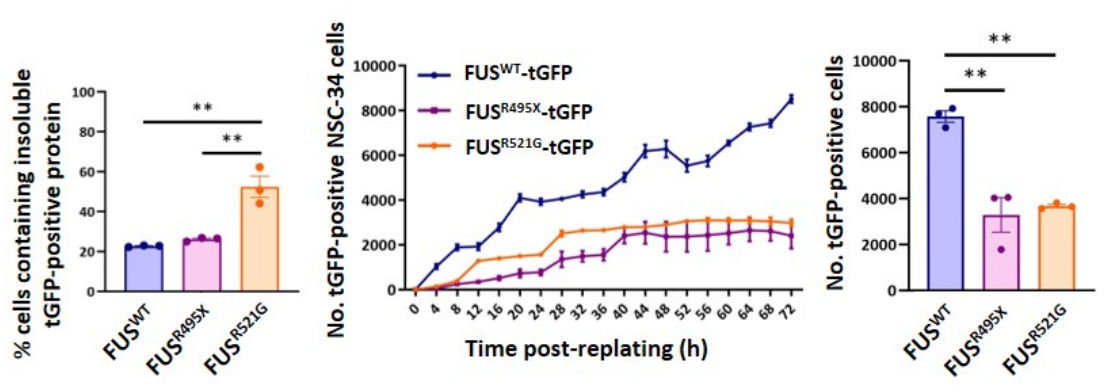

ii
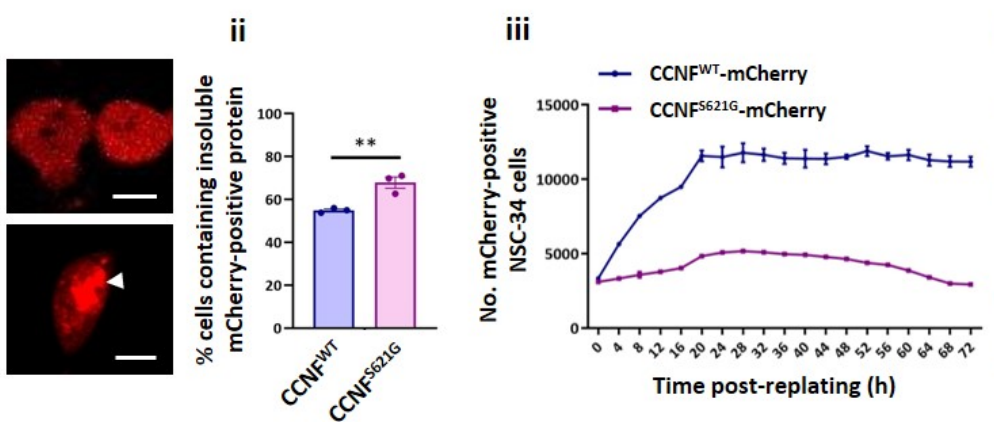

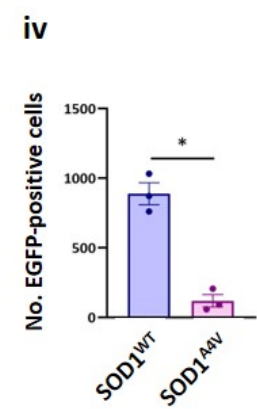

iv

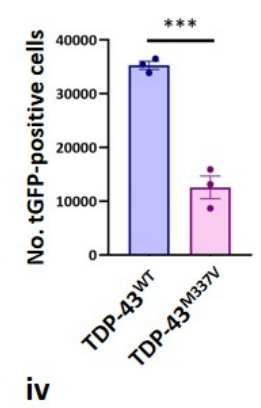

iv

iv

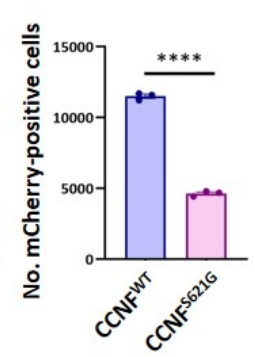

Figure 2. Characterising the localisation patterns and intracellular solubility of ALS-associated SOD1 ${ }^{\mathrm{AVV}}$, TDP-43 $^{\text {M337V }}$, FUS $^{\text {R495X }}$, FUS $^{\text {R521G }}$ and CCNF ${ }^{\text {S621G }}$. NSC-34 cells were transiently transfected with (A) SOD1 ${ }^{\text {WT }}$ EGFP or SOD1 ${ }^{\mathrm{A} 4 \mathrm{~V}}$-EGFP, (B) TDP-43 ${ }^{\mathrm{WT}}$-tGFP or TDP-43 ${ }^{\mathrm{M} 337 \mathrm{~V}}$-tGFP, (C) FUS ${ }^{\mathrm{WT}}$-tGFP, FUS ${ }^{\mathrm{R} 495 \mathrm{X}}$-tGFP or FUS $^{\mathrm{R} 521 \mathrm{G}}$-tGFP or (D) $\mathrm{CCNF}^{\mathrm{WT}}$-mCherry or CCNF ${ }^{\mathrm{S} 621 \mathrm{G}}$-mCherry. After $48 \mathrm{~h}$, transfected cells were either (i) imaged using a Leica TCS SP5 II confocal microscope, (ii) imaged on an IncuCyte ${ }^{\circledR}$ ZOOM, followed by incubation with $0.03 \%(\mathrm{w} / \mathrm{v})$ saponin in PBS for $10 \mathrm{~min}$ at room temperature, before being imaged again on the IncuCyte or (iii and iv) imaged in an IncuCyte ${ }^{\circledR}$ ZOOM over 72 h. (i) Representative images from confocal microscopy, with white arrow heads indicating inclusions formed by the EGFP/tGFP/mCherry-fusion proteins. Scale bars represent $10 \mu \mathrm{m}$. (ii) Cells were transfected in quadruplicate, and the data presented is the mean $\pm \mathrm{SEM}$ of the percentage of transfected NSC-34 cells containing insoluble EGFP-/tGFP-/mCherry-positive protein 
following permeabilisation with saponin. (iii) Numbers of EGFP/tGFP/mCherry-positive transfected cells over $72 \mathrm{~h}$ and (iv) the mean \pm SEM numbers of transfected cells at $48 \mathrm{~h}$ post-replating, in triplicate wells of cells. Differences between the means were determined using Student's t test or one-Way ANOVA followed by Tukey's Multiple Comparison Test. * indicates $p<0.05$, ** indicates $p<0.01, * * *$ indicates $p<0.001$ and $* * * *$ indicates $p<0.0001$.

\subsection{Localisation and aggregation of mutant SOD1, TDP-43, FUS and CCNF}

Inclusions of ALS-associated proteins are generally 2-20 $\mu \mathrm{m}$ in diameter in both human postmortem tissue [27, 30-33] and in cell culture models [34-39]. A size minimum of $2 \mu \mathrm{m}$ was thus established as suitable for categorising fluorescent foci as inclusions. The foci formed by SOD1 ${ }^{\mathrm{A} 4 \mathrm{~V}}$-EGFP, TDP-43 ${ }^{\mathrm{M} 337 \mathrm{~V}_{-}}$-tGFP, FUS ${ }^{\mathrm{R} 495 \mathrm{X}_{-} \mathrm{tGFP}}, \mathrm{FUS}^{\mathrm{R} 521 \mathrm{G}_{-} \mathrm{tGFP}}$ and $\mathrm{CCNF}^{\mathrm{S} 621 \mathrm{G}_{-}}$ mCherry were manually examined in images of cells and were consistently measured to be larger than $2 \mu \mathrm{m}$ (Figure 2, a, i-d, i).

While SOD $1^{\text {WT }}$-EGFP was observed to have a relatively even distribution throughout the cytoplasm and within nuclei, in a proportion of cells $\mathrm{SOD} 1^{\mathrm{A} 4 \mathrm{~V}}$-EGFP formed multiple large inclusions in the cytoplasm (Figure 2, a, i). Saponin-permeabilisation showed that there was no fluorescent signal from cells overexpressing SOD1 ${ }^{\mathrm{WT}}$-EGFP following permeabilisation, indicating that SOD $1^{\text {WT }}$-EGFP remained soluble in all cells that were imaged (Figure 2, a, ii). In accordance with the confocal microscopy data, a significantly greater percentage of cells $(10.38 \pm 0.27 \%)$ expressing SOD1 ${ }^{\mathrm{A} 4 \mathrm{~V}}$-EGFP remained EGFP-positive following permeabilisation $(p<0.0001)$, indicating that SOD1 $1^{\mathrm{A} 4 \mathrm{~V}}$-EGFP was present in an insoluble, non-diffusable form in a proportion of cells.

Imaging transfected cells using confocal microscopy, it was observed that TDP-43 ${ }^{\mathrm{WT}}$ and FUS $^{\mathrm{WT}}$ remained localised to cell nuclei, while the TDP-43 and FUS mutants mislocalised to the cytoplasm and formed large aggregates and smaller foci, as is observed in ALS patient tissue (Figure 2, b, i and c, i) [3, 4, 24]. Although TDP-43 ${ }^{\mathrm{WT}}$-tGFP was not observed to mislocalise and accumulate into cytoplasmic inclusions when cells were examined using confocal microscopy, TDP-43 ${ }^{\mathrm{WT}}$-tGFP was found to remain inside $55.22 \pm 0.69 \%$ of transfected cells after plasma membrane permeabilisation (Figure 2, b, ii). However, a significantly greater percentage of cells expressing TDP-43 ${ }^{\mathrm{M} 337 \mathrm{~V}}$-tGFP were tGFP-positive following permeabilisation $(79.41 \pm 2.18 \%)$ compared to cells expressing TDP- $43^{\mathrm{WT}}$-tGFP ( $p$ $=0.0035)$. TDP-43 ${ }^{\mathrm{WT}}$-tGFP that was bound to immobile elements or granules may not have been released when cells were incubated with saponin solution. In this case, the saponinpermeabilisation assay may not be appropriate for assaying the formation of TDP-43 cytoplasmic inclusions. Similarly, while FUS ${ }^{\mathrm{WT}}$-tGFP was not observed to mislocalise and accumulate into cytoplasmic inclusions when transfected cells were examined using confocal microscopy, the saponin-permeabilisation assay quantified that FUS ${ }^{\mathrm{WT}}$-tGFP remained in $22.72 \pm 0.25 \%$ of cells following incubation with saponin solution (Figure 2, c, ii). Moreover, the percentage of cells expressing FUS ${ }^{\mathrm{R} 495 \mathrm{X}}$-tGFP that remained tGFP-positive following permeabilisation $(26.15 \pm 0.56 \%)$ was similar to that of cells expressing FUS ${ }^{\text {WT }}$-tGFP. However, there was a significantly greater percentage of cells expressing FUS $^{\mathrm{R} 521 \mathrm{G}}$-tGFP that remained tGFP-positive $(52.4 \pm 5.29 \%)$ compared to both cells expressing FUS ${ }^{\mathrm{WT}}$-tGFP and cells expressing FUS ${ }^{\mathrm{R} 495 \mathrm{X}}$-tGFP $\left(\mathrm{FUS}^{\mathrm{WT}}-\mathrm{tGFP}, p=0.0012\right.$ FUS $^{\mathrm{R} 495 \mathrm{X}}$-tGFP, $p=0.0023$ ). As 
noted above, when cells expressing the FUS-tGFP constructs were examined using confocal microscopy, there was extensive formation of small foci $(<2 \mu \mathrm{m})$ and large aggregates by both FUS mutants (Figure 2, c, i). Thus, the similar percentages of cells expressing FUS ${ }^{\mathrm{WT}}$-tGFP and FUS ${ }^{\mathrm{R} 495 \mathrm{X}}$-tGFP that remained tGFP-positive after saponin-permeabilisation compared to the marked differences in their localisation patterns indicates that the saponin-permeabilisation assay may not be appropriate for measuring the formation of insoluble cytoplasmic mutant FUS-tGFP inclusions.

Since the original identification of the $C C N F^{S 621 G}$ mutation in ALS and frontotemporal dementia patients [25], the localisation patterns of $\mathrm{CCNF}^{\mathrm{S} 621 \mathrm{G}}$ in motor neurons have not been investigated in detail. However, Lee et al. [40] observed $\mathrm{CCNF}^{\mathrm{S} 621 \mathrm{G}}$ localised to inclusion-like structures while $\mathrm{CCNF}^{\mathrm{WT}}$ displayed diffuse distribution. We observed mCherry-tagged $\mathrm{CCNF}^{\mathrm{WT}}$ fluorescence with diffuse distribution in all imaged cells (Figure 2, d, i). In contrast, $\mathrm{CCNF}^{\mathrm{S} 621 \mathrm{G}}$-mCherry formed into large amorphous aggregates ranging from 5 to $>10 \mu \mathrm{m}$. Interestingly, saponin-permeabilisation revealed that both $\mathrm{CCNF}^{\mathrm{WT}}$-mCherry and $\mathrm{CCNF}^{\mathrm{S} 621 \mathrm{G}_{-}}$ mCherry formed extensively into insoluble structures, with $>50 \%$ of both cells transfected with $\mathrm{CCNF}^{\mathrm{WT}}$-mCherry cells and $\mathrm{CCNF}^{\mathrm{S} 621 \mathrm{G}}$-mCherry cells containing insoluble mCherrypositive protein (Figure 2, d, ii). Nevertheless, there were significantly more $\mathrm{CCNF}^{\mathrm{S} 621 \mathrm{G}_{-}}$ mCherry-expressing cells containing insoluble mCherry-positive protein $(67.84 \pm 2.61 \%)$ than there were of $\mathrm{CCNF}^{\mathrm{WT}}$-mCherry cells $(54.89 \pm 0.64 \%)(p=0.0085)$.

\subsection{HCA assay for proteostasis stress in cells expressing $\mathrm{SOD1}^{\mathrm{A4V}}$ and $\mathrm{CCNF}^{\mathrm{S621G}}$}

The optimised HCA SpotDetector BioApplication was used to compare the effect of SOD1 and CCNF variant overexpression on the ability of the cellular protein quality control network to prevent aggregation of conformationally-destabilised, aggregation-prone mutants of firefly luciferase (Fluc) [41-45]. It was reasoned that reductions in protein quality control network capacity would lead to increased aggregation of the EGFP-tagged Fluc mutants [41].

We detected $>90 \%$ of ECFP- and EGFP-positive cells (green circular masks). 'Spot' masks (yellow masks) were observed only on large foci with high fluorescence intensity, corresponding to the inclusion size and fluorescence intensity cut-offs established during assay optimisation. 
A
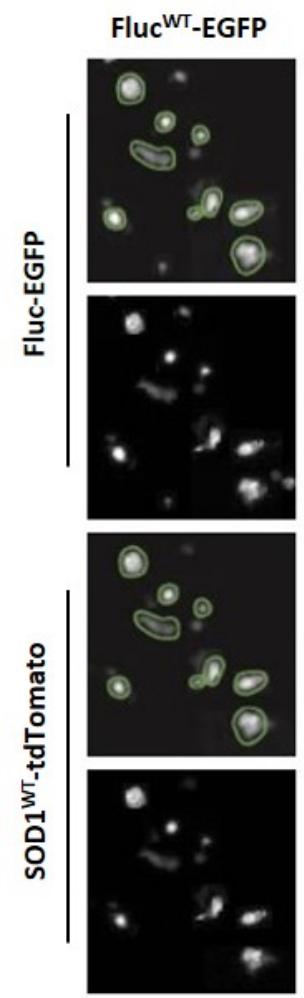

C
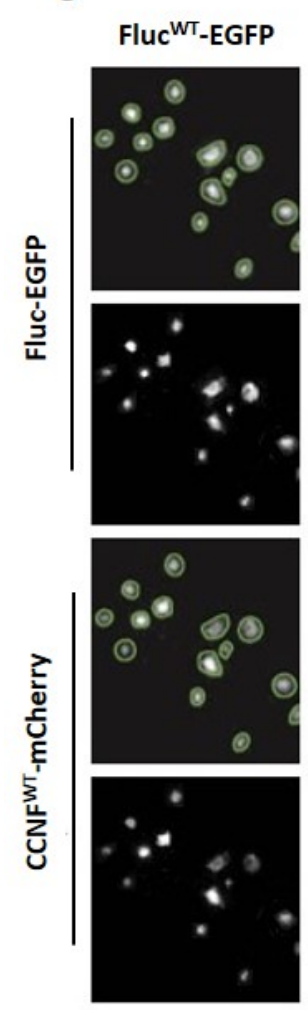

Fluc $^{\text {SM-EGFP }}$
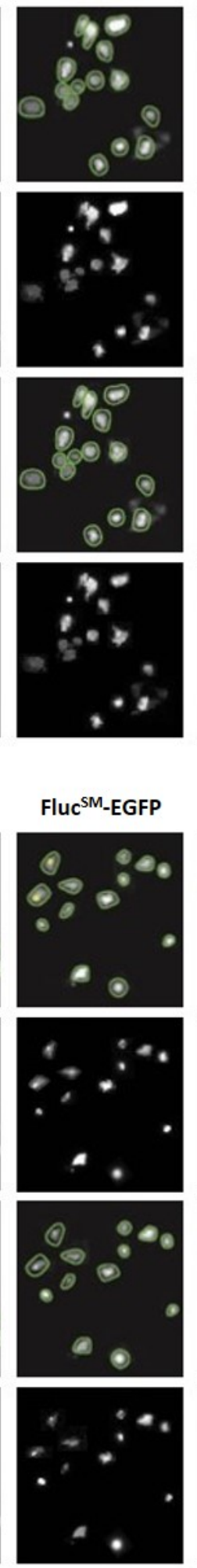
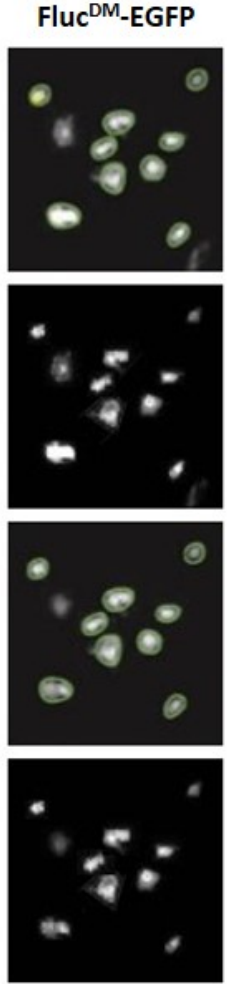

Fluc $^{\text {DM-EGFP }}$
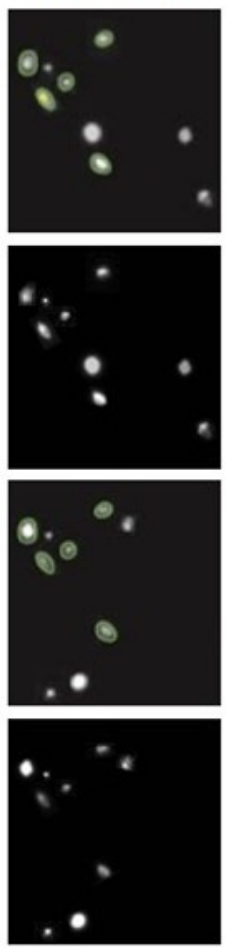

B
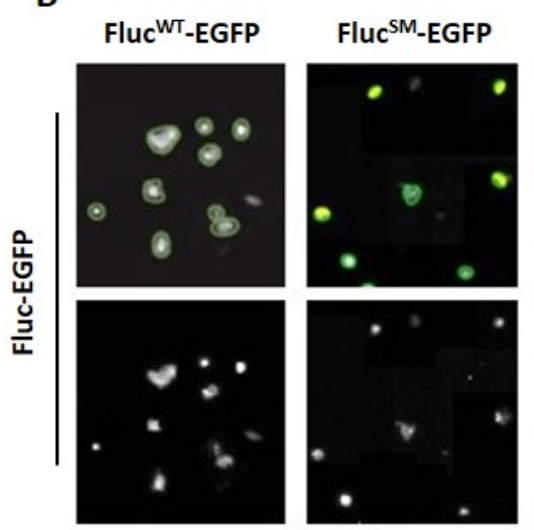

Fluc $^{\text {DM }}$-EGFP
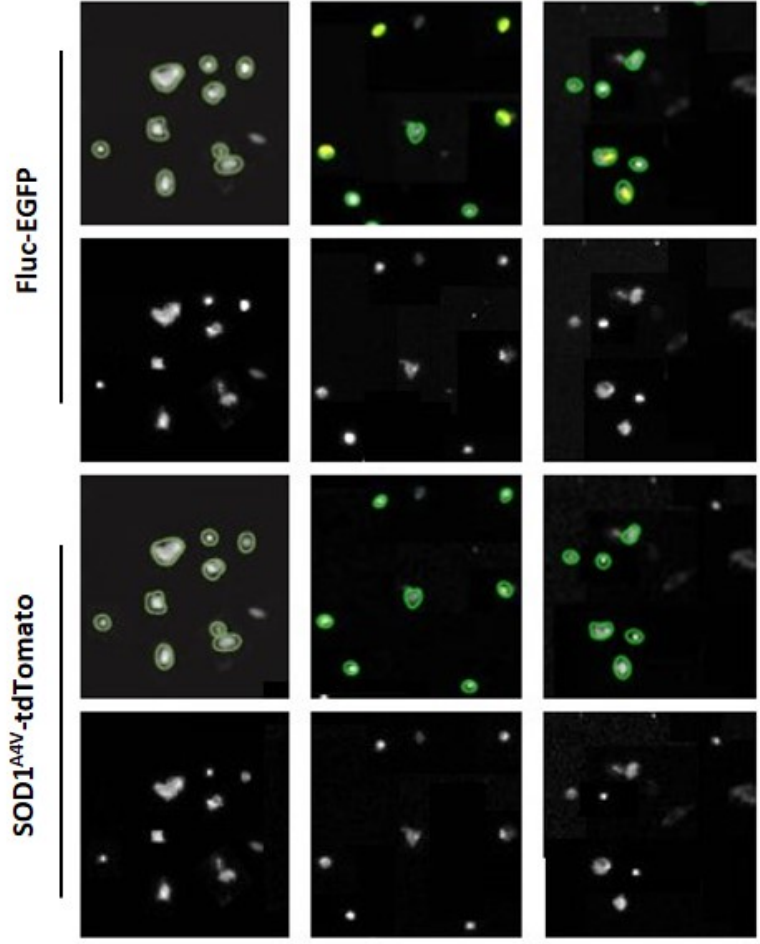

D
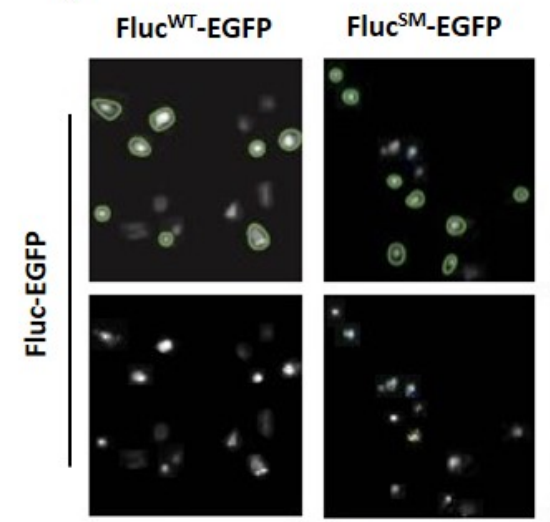

Fluc $^{\text {DM-EGFP }}$
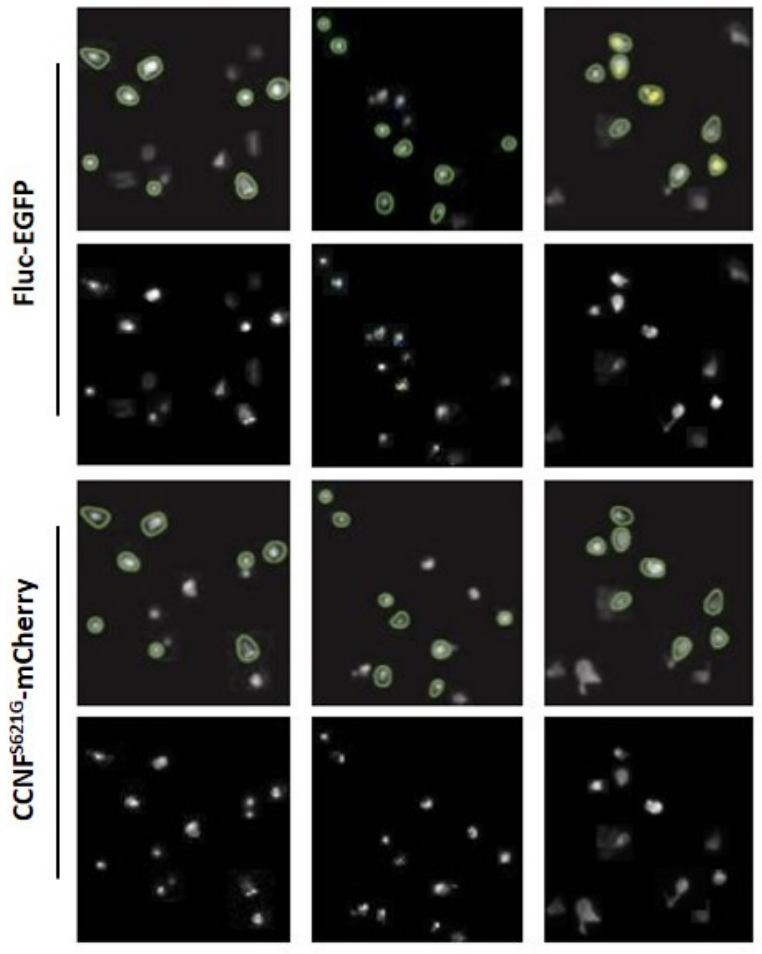

Figure 3. Optimised HCA SpotDetector BioApplication identifies and analyses transfected cells and FlucEGFP foci. Representative Cellomics ${ }^{\circledR}$ ArrayScan ${ }^{\mathrm{TM}}$ VTI images showing masks (first and third rows of each panel) used to identify and select NSC-34 cells co-transfected with either (A) SOD1 ${ }^{\mathrm{WT}}$-tdTomato, (B) SOD1 ${ }^{\mathrm{A} 4 \mathrm{~V}}$ tdTomato, (C) CCNF ${ }^{\mathrm{WT}}$-mCherry or (D) $\mathrm{CCNF}^{\mathrm{S} 621 \mathrm{G}}$-mCherry and Fluc ${ }^{\mathrm{WT}}$-EGFP, Fluc ${ }^{\mathrm{SM}}$-EGFP or Fluc ${ }^{\mathrm{DM}}$-EGFP. Cells were imaged at $48 \mathrm{~h}$ post-transfection. Green circular masks indicate cells selected for analysis, yellow 
masks indicate 'spots' selected for analysis, representing aggregates. Images were acquired using a $20 \times$ objective lens.

Proteasome inhibition of cells expressing mCherry alone confirmed that increased proteome stress results in increased aggregation of the Fluc-EGFP isoforms. Cells expressing mCherry that were treated with MG132 developed significantly greater numbers of Fluc ${ }^{\text {WT }}$-EGFP $(p<$ $0.0001)$, Fluc ${ }^{\text {SM }}$-EGFP $(p<0.0001)$ and Fluc ${ }^{\text {DM }}$-EGFP $(p<0.0001)$ aggregates compared to untreated cells (Figure 4, a, i). MG132 treatment resulted in significantly higher numbers of Fluc $^{\text {WT }}$-EGFP aggregates than Fluc ${ }^{\text {DM }}$-EGFP aggregates $(p=0.0153)$. Fluc ${ }^{\text {WT }}$-EGFP aggregates were significantly smaller $(p=0.002)$ and more brightly fluorescent $(p<0.0001)$ than Fluc ${ }^{\text {DM }}$-EGFP aggregates (Figure 4, b, i and c, i). Aggregates of the Fluc-EGFP isoforms were also detected in cells expressing SOD1-tdT, with a significant increase in the numbers of aggregates formed in cells expressing SOD $1^{\mathrm{A} 4 \mathrm{~V}}$-tdT compared to SOD $1^{\mathrm{WT}}$-tdT (Fluc ${ }^{\mathrm{WT}}$-EGFP, $p=0.0331$; Fluc ${ }^{\mathrm{SM}}$-EGFP, $p=0.0061$; Fluc ${ }^{\mathrm{DM}}$-EGFP, $p=0.0042$ ) (Figure 4, a, ii). There were also increases in the mean size of Fluc ${ }^{\mathrm{DM}}$-EGFP aggregates $(p=0.0430)$ and fluorescence intensity of aggregates of Fluc ${ }^{\text {WT }}$-EGFP $(p<0.0001)$, Fluc ${ }^{\text {SM }}$-EGFP $(p<0.0001)$ and Fluc ${ }^{\text {DM }}$ EGFP $(p<0.0001)$ in cells expressing SOD $1^{\mathrm{A} 4 \mathrm{~V}}$-tdT compared to SOD $1^{\mathrm{WT}}$-tdT (Figure $4, \mathrm{~b}$, ii and $c$, ii). Interestingly, aggregation of Fluc ${ }^{\mathrm{SM}}$-EGFP and Fluc ${ }^{\mathrm{DM}}$-EGFP was as extensive in cells expressing $\mathrm{CCNF}^{\mathrm{WT}}$-mCherry as those expressing $\mathrm{CCNF}^{\mathrm{S} 621 \mathrm{G}}$-mCherry (Figure 4, a, iii). Whilst aggregates of Fluc ${ }^{\mathrm{WT}}$-EGFP were also detected, there were significantly lower numbers of cells containing them compared to the numbers of cells containing aggregates of Fluc ${ }^{\mathrm{SM}}$ EGFP $(p<0.001)$ and Fluc ${ }^{\text {DM }}$-EGFP $(p<0.0001)$, both in cells expressing CCNF ${ }^{\text {WT }}$-mCherry and cells expressing $\mathrm{CCNF}^{\mathrm{S} 621 \mathrm{G}}$-mCherry. There was also the same trend in the size of aggregates of the Fluc-EGFP isoforms in cells expressing $\mathrm{CCNF}^{\mathrm{WT}}$-mCherry and those expressing $\mathrm{CCNF}^{\mathrm{S} 621 \mathrm{G}}$-mCherry, with significantly larger aggregates of Fluc ${ }^{\mathrm{DM}}$-EGFP formed than aggregates of Fluc ${ }^{\mathrm{WT}}$-EGFP $\left(\mathrm{CCNF}^{\mathrm{WT}}\right.$-mCherry, $p=0.0395$ CCNF $^{\mathrm{S} 621 \mathrm{G}}$-mCherry, $p=$ 0.0328 ) (Figure $4, b$, iii). There was no difference in the mean fluorescence intensity of the Fluc-EGFP aggregates of the Fluc-EGFP isoforms between cells expressing $\mathrm{CCNF}^{\mathrm{WT}}$-mCherry and cells expressing $\mathrm{CCNF}^{\mathrm{S} 621 \mathrm{G}}$-mCherry (Figure 4, c, iii). 

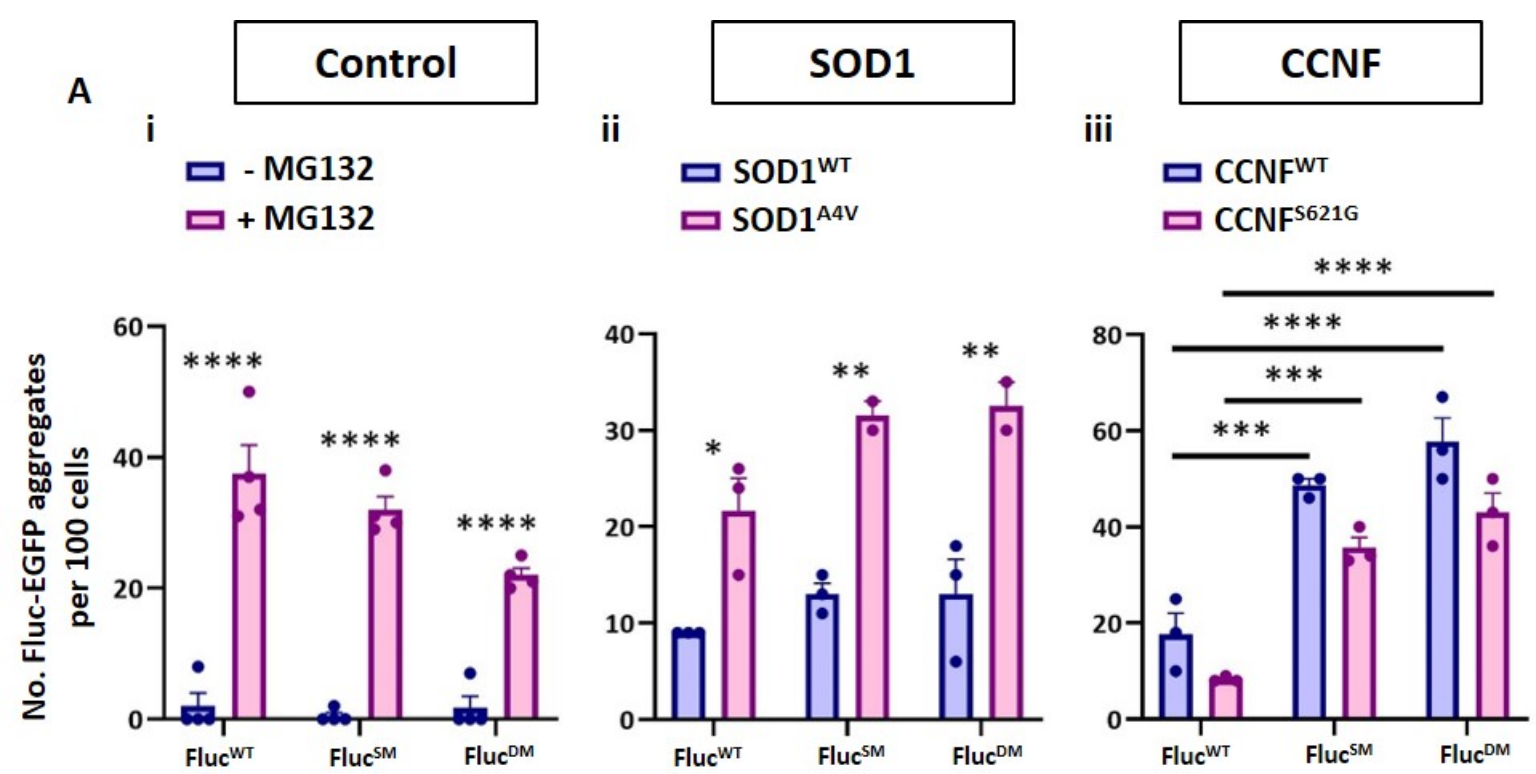

B
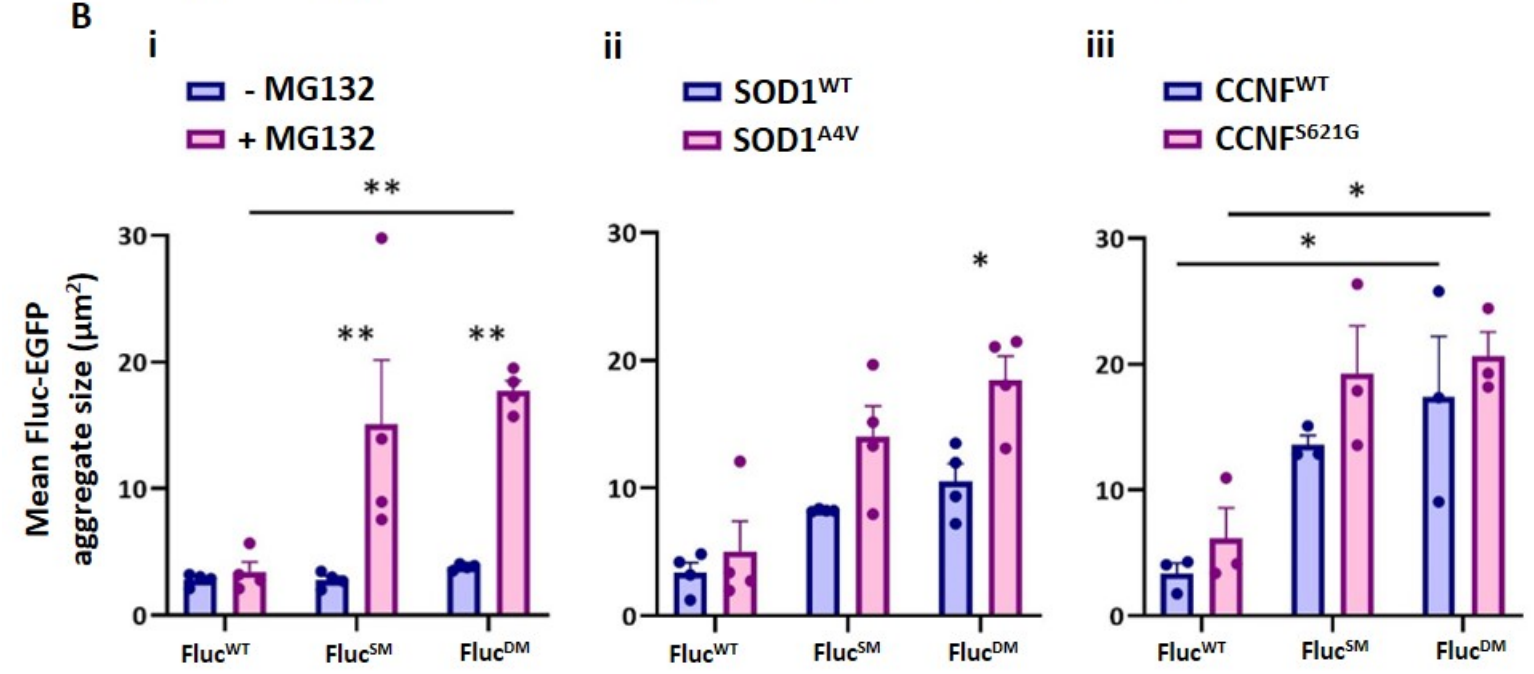
C i

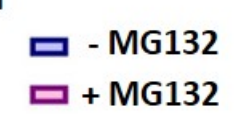

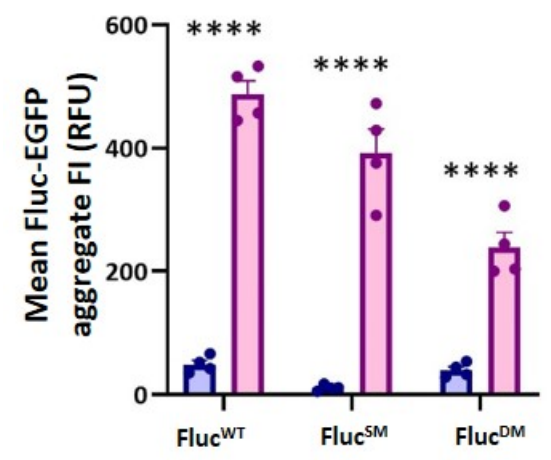

ii

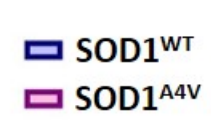
iii

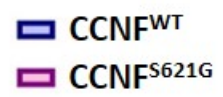

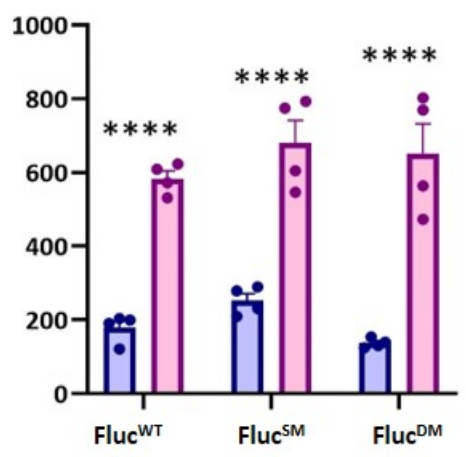

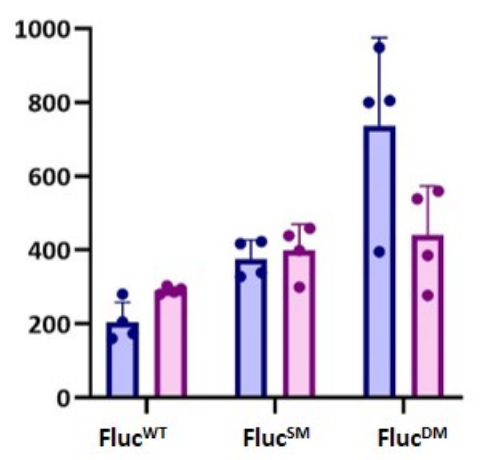

Figure 4. Firefly luciferase mutants report on chaperone network activity in NSC-34 cells expressing SOD1 and CCNF. (A) Numbers of Fluc-EGFP aggregates per 100 transfected cells, (B) mean size of Fluc-EGFP aggregates $\left(\mu \mathrm{m}^{2}\right)$ and $(\mathrm{C})$ mean fluorescence intensity (FI) of Fluc-EGFP aggregates imaged at $48 \mathrm{~h}$ posttransfection in NSC-34 cells expressing (i) mCherry alone \pm treatment with $5 \mu \mathrm{M}$ MG132, (ii) SOD $1{ }^{\mathrm{WT}}$-tdTomato or SOD1 ${ }^{\mathrm{A} 4 \mathrm{~V}}$-tdTomato or (iii) $\mathrm{CCNF}^{\mathrm{WT}}$-mCherry or $\mathrm{CCNF}^{\mathrm{S} 621 \mathrm{G}}$-mCherry. Treatment with MG132 was carried out 
at $30 \mathrm{~h}$ post-transfection. For mock treatment, $5 \mu \mathrm{M}$ DMSO was instead added to cells. Graphs represent the mean \pm SEM from quadruplicate wells of cells in $\mathrm{n}=1$ experiment. Differences between the means were determined using one-Way ANOVA followed by Tukey's Multiple Comparison Test. * indicates $p<0.05$, ** indicates $p<$ $0.01, * * *$ indicates $p<0.001, * * * *$ indicates $p<0.0001$. 


\section{DISCUSSION}

The genetic heterogeneity of ALS distinguishes it from most other neurodegenerative diseases, which can be linked to a limited number of pathogenic mechanisms and phenotypes. The ALS research field would benefit greatly from the use of experimental systems with HCA capacity to help navigate through the complexity of ALS. To address this, we have developed an HCA methodology to use with cellular ALS models. The overall objective of this work was to develop a system that could be used to collect descriptive phenotypic data from cellular ALS models that would enable (1) characterisation of the inclusion formation pathways of different ALS-associated proteins, and (2) the use of diverse markers of proteome stress and motor neuron dysfunction to assess potential therapeutic compounds and genetic modifiers of ALS disease mechanisms and toxicity.

The NSC-34 models of ALS generated here were examined for the localisation, mobility and solubility of the fusion proteins. The aim of these studies was to establish disease phenotypes that could be used in an experimental system with HCA capacity for further studies into disease mechanisms, and potentially for evaluation of candidate therapeutics. This HCA experimental system was generated through optimising the SpotDetector BioApplication to investigate reductions in cellular protein folding/re-folding capacity caused by WT and mutant SOD1 and CCNF. Analysis was facilitated by co-expression of conformationally-destablised Fluc-EGFP mutants [41] with WT and mutant SOD1 and CCNF. We hypothesised that dysregulation of proteostasis mechanisms that may be exacerbated by ALS-associated mutations would overload cellular proteostasis capacity, resulting in inability of the cellular pool of molecular chaperones to prevent aggregation of the Fluc-EGFP mutants. The optimised SpotDetector BioApplication enabled quantification of the numbers, mean size and fluorescence intensity of aggregates formed by the Fluc-EGFP isoforms.

The ability of the Fluc-EGFP mutants to report on proteome stress was confirmed through proteasome inhibition of cells expressing mCherry alone. In MG132-treated cells, Fluc ${ }^{\text {WT }}$ EGFP aggregates that formed were smaller than the aggregates formed by Fluc ${ }^{\mathrm{SM}}$-EGFP and Fluc ${ }^{\mathrm{DM}}$-EGFP, indicating that less of the WT protein misfolded and accumulated into aggregates. Without exogenous proteome stress induced by proteasome inhibition, there was negligible aggregation of the Fluc-EGFP isoforms, demonstrating that they were able to report on increased proteome stress.

The data from the present work demonstrates that the optimised Fluc-EGFP HCA assay is able to report on reduced activity of the chaperone network resulting from the expression of SOD $1^{\mathrm{A} 4 \mathrm{~V}}$ as previously reported [46-48]. The overexpression of $\mathrm{CCNF}^{\mathrm{WT}}$-mCherry caused the same extent of Fluc-EGFP aggregation as $\mathrm{CCNF}^{\mathrm{S} 621 \mathrm{G}}$-mCherry, indicating that mutant $\mathrm{CCNF}$ did not differentially affect chaperone activity compared to $\mathrm{CCNF}^{\mathrm{WT}}$. CCNF is an important protein in the ubiquitin-proteasome system, as a mediator of protein ubiquitylation [49]. Ubiquitylation of target proteins is altered in cells expressing mutant CCNF, causing aberrant accumulation of ubiquitylated proteins and consequent stress on the proteostasis network [25]. The data obtained from the Fluc-EGFP HCA assay developed in the present work suggests that 
proteostasis disruption caused by mutant CCNF does not involve impairment of the protein folding/re-folding activity of chaperones.

The Fluc-EGFP isoforms were designed to act as sensors of cellular protein folding/re-folding capacity that would themselves have minimal biological impact in most of the commonly used cellular and animal models [41]. In the present work it was demonstrated that they are suitable for use in an HCA assay format to report on disruptions in the activity of the cellular chaperone network. In future work it would be useful to optimise an HCA assay that utilises changes in luminescence activity of the Fluc-EGFP isoforms [41] as an additional measure.

In addition to the use of this Fluc-EGFP HCA assay to examine cellular models of SOD1 ${ }^{\mathrm{A} 4 \mathrm{~V}}$ and $\mathrm{CCNF}^{\mathrm{S} 621 \mathrm{G}}$, it would be useful in future work to utilise this assay to examine the cellular models of mutant TDP-43, FUS, UBQLN2, OPTN, VAPB and VCP generated in this work. Beyond establishing ALS-associated mutant proteins that impair the activity of the chaperone network in cells, this HCA assay could have potential for application in studies to screen for drugs that ameliorate chaperone activity impairment. 
bioRxiv preprint doi: https://doi.org/10.1101/2021.09.23.461468; this version posted September 23, 2021. The copyright holder for this preprint (which was not certified by peer review) is the author/funder. All rights reserved. No reuse allowed without permission.

\section{Funding \& Acknowledgements}

J.J.Y. was supported by a University of Wollongong Professorship in Neurodegenerative Diseases, and by an National Health and Medical Research Council, Australia Dementia Teams Grant (1095215) and Investigator Grant (1194872).

\section{REFERENCES}

1. Mackenzie, I.R., et al., Pathological TDP-43 distinguishes sporadic amyotrophic lateral sclerosis from amyotrophic lateral sclerosis with SOD1 mutations. Ann Neurol, 2007. 61(5): p. 427-34.

2. Kwong, L.K., et al., TDP-43 proteinopathy: the neuropathology underlying major forms of sporadic and familial frontotemporal lobar degeneration and motor neuron disease. Acta Neuropathol, 2007. 114(1): p. 63-70.

3. Kwiatkowski, T.J., Jr., et al., Mutations in the FUS/TLS gene on chromosome 16 cause familial amyotrophic lateral sclerosis. Science, 2009. 323(5918): p. 1205-8.

4. Vance, C., et al., Mutations in FUS, an RNA processing protein, cause familial amyotrophic lateral sclerosis type 6. Science, 2009. 323(5918): p. 1208-1211.

5. Bolognesi, B., et al., ANS binding reveals common features of cytotoxic amyloid species. ACS Chem Biol, 2010. 5(8): p. 735-40.

6. $\quad$ Proctor, E.A., et al., Nonnative SOD1 trimer is toxic to motor neurons in a model of amyotrophic lateral sclerosis. Proc Natl Acad Sci U S A, 2016. 113(3): p. 614-9.

7. Zhu, C., et al., Large SOD1 aggregates, unlike trimeric SOD1, do not impact cell viability in a model of amyotrophic lateral sclerosis. Proc Natl Acad Sci U S A, 2018. 115(18): p. 4661-4665.

8. Johnston, J.A., C.L. Ward, and R.R. Kopito, Aggresomes: a cellular response to misfolded proteins. J Cell Biol, 1998. 143(7): p. 1883-98.

9. Kopito, R.R., Aggresomes, inclusion bodies and protein aggregation. Trends Cell Biol, 2000. 10(12): p. 524-30.

10. Kawaguchi, Y., et al., The deacetylase HDAC6 regulates aggresome formation and cell viability in response to misfolded protein stress. Cell, 2003. 115(6): p. 727-38.

11. Arrasate, M., et al., Inclusion body formation reduces levels of mutant huntingtin and the risk of neuronal death. Nature, 2004. 431(7010): p. 805-10.

12. Kaganovich, D., R. Kopito, and J. Frydman, Misfolded proteins partition between two distinct quality control compartments. Nature, 2008. 454(7208): p. 1088-95.

13. Tan, J.M., et al., Lysine 63-linked ubiquitination promotes the formation and autophagic clearance of protein inclusions associated with neurodegenerative diseases. Hum Mol Genet, 2008. 17(3): p. 431-9.

14. Treusch, S., D.M. Cyr, and S. Lindquist, Amyloid deposits: protection against toxic protein species? Cell Cycle, 2009. 8(11): p. 1668-74.

15. Zhang, X. and S.B. Qian, Chaperone-mediated hierarchical control in targeting misfolded proteins to aggresomes. Mol Biol Cell, 2011. 22(18): p. 3277-88.

16. Weisberg, S.J., et al., Compartmentalization of superoxide dismutase 1 (SOD1G93A) aggregates determines their toxicity. Proc Natl Acad Sci U S A, 2012. 109(39): p. 15811-6.

17. Polling, S., et al., Misfolded polyglutamine, polyalanine, and superoxide dismutase 1 aggregate via distinct pathways in the cell. J Biol Chem, 2014. 289(10): p. 6669-80.

18. Grad, L.I., et al., Intercellular propagated misfolding of wild-type Cu/Zn superoxide dismutase occurs via exosome-dependent and-independent mechanisms. Proc Natl Acad Sci U S A, 2014. 111. 
19. McAlary, L., et al., Prion-Like Propagation of Protein Misfolding and Aggregation in Amyotrophic Lateral Sclerosis. Frontiers in Molecular Neuroscience, 2019. 12(262).

20. Yerbury, J.J., et al., Walking the tightrope: proteostasis and neurodegenerative disease. J Neurochem, 2016. 137(4): p. 489-505.

21. Yerbury, J.J., N.E. Farrawell, and L. McAlary, Proteome Homeostasis Dysfunction: A Unifying Principle in ALS Pathogenesis. Trends in Neurosciences, 2020. 43(5): p. 274284.

22. Cashman, N.R., et al., Neuroblastomax Spinal Cord (NSC) Hybrid Cell Lines Resemble Developing Motor Neurons. Dev Dynam, 1992. 194.

23. Deng, H.X., et al., Amyotrophic lateral sclerosis and structural defects in $\mathrm{Cu}, \mathrm{Zn}$ superoxide dismutase. Science, 1993. 261(5124): p. 1047.

24. Tamaoka, A., et al., TDP-43 M337V mutation in familial amyotrophic lateral sclerosis in Japan. Intern Med, 2010. 49(4): p. 331-4.

25. Williams, K.L., et al., CCNF mutations in amyotrophic lateral sclerosis and frontotemporal dementia. Nat Commun, 2016. 7: p. 11253.

26. Deng, H.X., et al., Mutations in UBQLN2 cause dominant X-linked juvenile and adultonset ALS and ALS/dementia. Nature, 2011. 477(7363): p. 211-5.

27. Maruyama, H., et al., Mutations of optineurin in amyotrophic lateral sclerosis. Nature, 2010. 465(7295): p. 223-6.

28. Nishimura, A.L., et al., A Mutation in the Vesicle-Trafficking Protein VAPB Causes Late-Onset Spinal Muscular Atrophy and Amyotrophic Lateral Sclerosis. American Journal of Human Genetics, 2004. 75(5): p. 822-831.

29. Johnson, J.O., et al., Exome sequencing reveals VCP mutations as a cause of familial $A L S$. Neuron, 2010. 68(5): p. 857-64.

30. Shibata, N., et al., Cu/Zn superoxide dismutase-like immunoreactivity in Lewy bodylike inclusions of sporadic amyotrophic lateral sclerosis. Neurosci Lett, 1994. 179(12): p. 149-52.

31. Leigh, P.N., et al., Ubiquitin-immunoreactive intraneuronal inclusions in amyotrophic lateral sclerosis. Morphology, distribution, and specificity. Brain, 1991. 114 ( Pt 2): p. 775-88.

32. Strong, M.J., S. Kesavapany, and H.C. Pant, The pathobiology of amyotrophic lateral sclerosis: a proteinopathy? J Neuropathol Exp Neurol, 2005. 64(8): p. 649-64.

33. Teyssou, E., et al., Mutations in SQSTM1 encoding p62 in amyotrophic lateral sclerosis: genetics and neuropathology. Acta Neuropathol, 2013. 125(4): p. 511-22.

34. Matsumoto, G., S. Kim, and R.I. Morimoto, Huntingtin and mutant SOD1 form aggregate structures with distinct molecular properties in human cells. J Biol Chem, 2006. 281(7): p. 4477-85.

35. Johnston, J.A., Formation of high molecular weight complexes of mutant. 2000.97(23): p. 12571-6.

36. Matsumoto, G., et al., Structural properties and neuronal toxicity of amyotrophic lateral sclerosis-associated Cu/Zn superoxide dismutase 1 aggregates. J Cell Biol, 2005. 171(1): p. 75-85.

37. Cozzolino, M., Cysteine 111 Affects Aggregation and Cytotoxicity of Mutant Cu,Znsuperoxide Dismutase Associated with Familial Amyotrophic Lateral Sclerosis. 2008. 283(2): p. 866-74.

38. Kuijpers, M., et al., Amyotrophic lateral sclerosis (ALS)-associated VAPB-P56S inclusions represent an ER quality control compartment. Acta Neuropathol Commun, 2013. 1: p. 24.

39. Zeineddine, R., et al., SOD1 protein aggregates stimulate macropinocytosis in neurons to facilitate their propagation. Molecular Neurodegeneration, 2015. 10(1): p. 57. 
40. Lee, A., et al., Pathogenic mutation in the ALS/FTD gene, CCNF, causes elevated Lys48-linked ubiquitylation and defective autophagy. Cellular and Molecular Life Sciences, 2018. 75(2): p. 335-354.

41. Gupta, R., et al., Firefly luciferase mutants as sensors of proteome stress. Nat Methods, 2011. 8(10): p. 879-84.

42. Frydman, J., et al., Folding of nascent polypeptide chains in a high molecular mass assembly with molecular chaperones. Nature, 1994. 370(6485): p. 111-7.

43. Thulasiraman, V. and R.L. Matts, Effect of geldanamycin on the kinetics of chaperonemediated renaturation of firefly luciferase in rabbit reticulocyte lysate. Biochemistry, 1996. 35(41): p. 13443-50.

44. Nimmesgern, E. and F.U. Hartl, ATP-dependent protein refolding activity in reticulocyte lysate. Evidence for the participation of different chaperone components. FEBS Lett, 1993. 331(1-2): p. 25-30.

45. Schroder, H., et al., DnaK, DnaJ and GrpE form a cellular chaperone machinery capable of repairing heat-induced protein damage. Embo j, 1993. 12(11): p. 4137-44.

46. Tummala, H., et al., Inhibition of chaperone activity is a shared property of several $\mathrm{Cu}, \mathrm{Zn}$-superoxide dismutase mutants that cause amyotrophic lateral sclerosis. J Biol Chem, 2005. 280(18): p. 17725-31.

47. Takeuchi, H., et al., Hsp70 and Hsp40 improve neurite outgrowth and suppress intracytoplasmic aggregate formation in cultured neuronal cells expressing mutant SOD1. Brain Res, 2002. 949(1-2): p. 11-22.

48. Bruening, W., et al., Up-regulation of protein chaperones preserves viability of cells expressing toxic Cu/Zn-superoxide dismutase mutants associated with amyotrophic lateral sclerosis. J Neurochem, 1999. 72(2): p. 693-9.

49. D'Angiolella, V., M. Esencay, and M. Pagano, A cyclin without cyclin-dependent kinases: cyclin F controls genome stability through ubiquitin-mediated proteolysis. Trends Cell Biol, 2013. 23(3): p. 135-40.

\section{CRediT author statement}

Isabella A. Lambert-Smith: Conceptualisation, Methodology, Validation, Formal analysis, Investigation, Data curation, Writing - Original Draft, Visualisation. Justin J. Yerbury: Conceptualisation, Methodology, Formal analysis, Investigation, Resources, Writing - Review \& Editing, Visualisation, Supervision, Project administration, Funding acquisition. Darren N. Saunders: Conceptualisation, Methodology, Formal analysis, Investigation, Resources, Writing - Review \& Editing, Visualisation, Supervision, Project administration, Funding acquisition. 